\title{
SINERGIA
}

REVISTA DO INSTITUTO DE CIÊNCIAS ECONÔMICAS, ADMINISTRATIVAS E CONTÁBEIS (ICEAC)

\section{INCLUSÃO SOCIAL NO MERCADO DE TRABALHO: UM OLHAR SOBRE A DIVERSIDADE DE PESSOAS COM DEFICIÊNCIAS NA COTRIPAL DE PANAMBI-RS}

\author{
JAINE BARCELLOS DE OLIVEIRA \\ MICHEL BARBOZA MALHEIROS* \\ CAMILA CRISTINA DEIFELD"* \\ BRUNA ROBERTA BUENO*** \\ NATALIE RAFAELA FERRÃO BRANDÃO ${ }^{* * * * *}$
}

\begin{abstract}
RESUMO
Este estudo tem como objetivo analisar a inclusão de pessoas com deficiência no mercado de trabalho, especificamente na cooperativa Cotripal localizada na cidade de Panambi/RS, demonstrando as dificuldades existentes neste processo e também estimular a inclusão social no mercado de trabalho. Este estudo se classifica como qualitativo, tendo como base de dados de entrevistas das quais serão analisadas e tabuladas. Foi conduzida uma entrevista com a gestora de RH da organização e entrevistas com sete PcDs, as quais foram coletadas de modo documental. Com base nos resultados, percebe-se que a organização demorou a aderir o sistema de cotas. Tal fato é decorrente de a fiscalização ter começado a cobrar a inclusão social somente a partir de 2013 no interior do Estado do Rio Grande do Sul e que além da Cotripal investir em programas e treinamentos voltados para que a inclusão social seja realizada da melhor maneira dentro da organização.
\end{abstract}

Palavras-chave: Inclusão social. Pessoas com deficiência. Lei de Cotas.

\section{ABSTRACT}

This study aims to analyze the inclusion of people with disabilities in the labor market, specifically in the Cotripal cooperative located in the city of Panambi / RS, demonstrating the difficulties existing in this process and also stimulating social inclusion in the labor market. This study is classified as qualitative, having as database of interviews which will be analyzed and tabulated. An interview was conducted with the organization's HR manager and interviews with seven PwDs, which were collected in a documentary manner. Based on the results, it is clear that the organization was slow to adhere to the quota system. This is due to the fact that the inspection began to demand social inclusion only from 2013 in the interior of the State of Rio Grande do Sul and that in addition to Cotripal investing in programs and training aimed at ensuring that social inclusion is carried out in the best way within organization.

Keywords: Social inclusion. Disabled people. Quota Law.

Recebido em: 12-08-2020 Aceito em: 27-04-2021

\section{INTRODUÇÃO}

A busca pela inclusão de pessoas com deficiência $(P c D)$ no contexto organizacional é uma luta constante. Inserir pessoas que possuem suas limitações é um dos maiores desafios da sociedade. Por outro lado, um dos objetivos centrais da inclusão social consiste em combater o preconceito e reduzir as desigualdades que existem no meio social (LABBÉ et al. 2020). Desse modo, torna-se essencial que tais reflexões perpassem a esfera social e se estendam ao meio organizacional (contextos públicos, privados e cooperativos) (MEIRELLES, 2014; LO; PARK, 2020). O mercado de trabalho, da mesma forma, necessita estar ciente da diversidade existente no contexto em que se está inserido. Assim sendo, Meirelles (2014) ressalta que a inclusão social em organizações, seja ela pública ou privada, se apresenta como uma grande propulsora do desenvolvimento humano, o que não é diferente em ambientes de trabalho cooperativos.

Incluir as $\mathrm{PcD}$ é muito mais que um discurso ou um pensamento, é uma ação que exige

\footnotetext{
Graduanda em Administração pela Universidade Federal de Santa Maria (UFSM).

Graduação em Administração pela Universidade Federal de Santa Maria. Mestrando em Administração pelo Programa de PósGraduação em Administração (PPGA) na Universidade Federal de Santa Maria. E-mail: malheirosmb@gmail.com

*** Graduanda em Administração pela Universidade Federal de Santa Maria (UFSM).

*.*** Graduanda em Administração pela Universidade Federal de Santa Maria (UFSM).

***** Graduanda em Administração pela Universidade Federal de Santa Maria (UFSM).
} 
responsabilidade e seja posto em prática, pois como argumenta Silver (2016) a inclusão social é um processo que estimula e incentiva a interação social entre indivíduos com diferentes atributos socialmente ou que forneça acesso à participação em todas as esferas da vida social. Nesse aspecto, a inclusão social se apresenta como uma forte contribuição para o desenvolvimento humano, bem como contribuir para a geração de emprego e renda e o fortalecimento da cooperação (MEIRELLES, 2014).

No campo da Administração o processo de inclusão social abarca um dos maiores desafios para gestores de $\mathrm{RH}$ e de pessoas, visto que este processo envolve a adaptação, fornecimento de condições seguras de trabalho e interação com os colegas de trabalho. Nesse sentido, Malheiros et al. (2020a) destacaram que para a inclusão social ser eficaz é necessário ter uma cultura organizacional que seja direcionada a inclusão. De acordo com esse pensamento, os referidos autores mencionam como exemplo a importância de realizar workshops e eventos de conscientização no meio laboral para reforçar a importância da inclusão e o valor que as $\mathrm{PcD}$ podem agregar para a organização, tanto como pessoas, quanto profissionais. Fleury (2000) já havia mencionado que as PcD correspondem a um tipo de diversidade cultural e que agrega valor para a organização e pode ser usada de modo estratégico frente aos concorrentes.

No município de Panambi - RS, a prefeitura juntamente com as demais organizações existentes está empenhada na Inclusão de Pessoas com Deficiência, realizando eventos, dos quais podemos citar: o Seminário sobre Inclusão de Pessoas com Deficiência no Mercado de Trabalho: Caminho para o Mundo Profissional que foi realizado em agosto do ano de 2017 e que está na sua $4^{\circ}$ edição. O referido evento é promovido pelo Grupo de Articulação formado pelas diversas organizações do Município e que conta com o apoio da Secretaria Municipal de Educação e Cultura, Conselho Municipal dos Direitos da Pessoa com Deficiência (COMDEF), Serviço Nacional de Aprendizagem Industrial (SENAI/ RS e Serviço Social da Indústria - SESI) Centro de Atendimento Educacional Especializado (CAEEP). Onde tem por objetivo trazer conhecimento para a comunidade sobre a inclusão das PcDs apresentando os avanços da Legislação e as ações realizadas pelas organizações participantes do Grupo Articulação.

Nesse contexto, a organização (Cotripal) que é objeto do presente estudo, atua a 60 anos no mercado de trabalho e tem como enfoque o trabalho mútuo e priorizar a união. Contudo, focada na sua missão, a cooperativa é reconhecida por trabalhar com a inclusão social dentro da organização, dando oportunidade para muitas PcDs onde presta todo o suporte necessário. Segundo Lo e Park (2020) missões como esta fornecem oportunidades de sobrevivência e prosperidade para os colaboradores com deficiência. Por se tratar de uma cooperativa, Ghirardi (2004) argumenta que estas representam espaços de trabalho mais inclusivos para PcDs.

As cooperativas enquanto ambientes organizacionais que prezam pela cooperação também buscam ter um local de trabalho inclusivo. Conforme explicam Silva, Bolson e Ferrigoti (2016) a inclusão social em meios cooperativos ajuda a melhorar a relação entre os cooperados. Frente ao exposto, o presente estudo tem como objetivo analisar a inclusão social na cooperativa Cotripal no município de Panambi - RS. Para tanto, a questão de pesquisa que norteia esta estudo corresponde a: "como acontece a inclusão social na organização Cotripal do município Panambi - RS?".

Este estudo visa contribuir para a teoria no sentido de aprofundar o conhecimento em torno da temática inclusão social e $\mathrm{PcD}$, além de oferecer novos argumentos para reforçar a sua importância no meio laboral. De modo prático este estudo também buscou trazer de forma objetiva argumentos e informações que possam auxiliar gestores na aprimoração do trabalho com PcD e compreender a importância da inclusão para a valorização das organizações e seus colaboradores.

\section{REFERENCIAL TEÓRICO}

Nesta seção são expostas as ideias centrais relativas à temática inclusão social, PcD e diversidade.

\subsection{Inclusão social no trabalho e pessoas com deficiência (pcd)}

A inclusão das PcDs encontra prerrogativa legal a partir da Lei 8213/91, especificamente em seu Art. 93, que regulamenta um quantitativo de vagas para contratação. A distribuição de vagas a partir de 100 colaboradores será destinada a inclusão de deficientes $2 \%$ a $5 \%$ para os cargos disponíveis na organização da seguinte forma: até 200 colaboradores $2 \%$ das vagas são destinadas; de 201 a 500 colaboradores $3 \%$ são destinadas; de 501 a 1000 colaboradores 4\% são destinadas; a partir de 1001 colaboradores 5\% são destinadas (LARA, 2013).

A Lei no 8.213/91, chamada de Lei de Beneficiários da Previdência Social, mas popularmente chamada Lei de Cotas surgiu com o intuito de integrar as PcD no ambiente de trabalho. Essa Lei distribui vagas destinadas a PcDs nas empresas, a fim de proporcionar oportunidades e uma integração com a sociedade (BRASIL, 1991). Segundo Perlin et al. (2016) a inclusão das PcD faz parte da política de responsabilidade social de uma organização, e representa uma questão que vai além de uma questão social. 
No Art. 93 da Lei 8.213/91 é regulamentado que as organizações com 100 ou mais funcionários em seu quadro de colaboradores, devem beneficiar as PcDs de $2 \%$ a $5 \%$ com vagas, sendo distribuídas da seguinte forma: I- até 200 colaboradores, 2\%; II- de 201 a 500 colaboradores, 3\%; III- de 501 a 100 colaboradores, 4\%; e IV- a partir de 1001 colaboradores, 5\% (WALLERIUS; BISSANI, 2015).

Dessa forma, a inclusão social é definida como a percepção dos colaboradores sobre o que eles são permitidos participar de algo (MILLER, 1998). Esta "percepção" está focada no quanto o colaborador sentese parte dos processos organizacionais e, essencialmente, no que reflete aos processos de tomada de decisão, elaboração e definição de estratégias, acesso a informação, entre outros aspectos (MILLER, 1998). Já o conceito de Giovannini (2004) explica que a inclusão consiste no estado de ser ajudado, respeitado e valorizado. Para Meirelles (2014) a inclusão social contribui para o fortalecimento da cooperação entre indivíduos.

No entanto, a inclusão social nunca é absoluta, mas está intimamente associada aos indivíduos e sua percepção, consciência e conhecimento da situação, a um contexto específico ou a um período histórico e às condições estruturais da sociedade, como suas leis, normas e regulamentos (MATHIESON et al., 2008). Dessa forma, podendo ser influenciada por diversos fatores, a inclusão social poder ser considerada um construto bastante dinâmico. Assim, os eventos organizacionais, bem como momentos de conscientização, devem enfatizar que a inclusão está associada ao senso de conexão, pertencimento, direitos e deveres (MATHIESON et al., 2008; TAKET et al., 2013; MALHEIROS et al., 2020b).

Segundo Araujo (2012), houve uma necessidade de mudança de pensamento cultural referente à inclusão das PcDs no mercado de trabalho, onde a chegada delas promoveu um olhar positivo voltado às organizações e com a Lei das Cotas, felizmente esses indivíduos estão tendo uma oportunidade não só profissional, mas de se sentirem iguais e produtivos (PERLIN et al., 2016).

Frente a este contexto, compreender conceitos que definem uma $\mathrm{PcD}$, faz com que o assunto ganhe ainda mais evidência e se torne algo visível ao conhecimento, tanto para a sociedade quanto para as organizações. Segunda explica Camara (2004), conforme descrito no Art. o do Decreto 3.298/99 a deficiência é perda total ou anomalidade de uma estrutura ou função anatômica, fisiológica ou psicológica que acarrete na incapacidade do desempenho de uma atividade, dentro do padrão considero como "normal" para o ser humano (BACHE, 2019).

Nesse sentido, o conceito de deficiência pode ser compreendido como uma incapacidade que um indivíduo apresenta, causando uma restrição e que podem ser classificados de diversas formas: i) linguagem: incapacidade de falar; ii) audição ou sensorial: incapacidade de ouvir e dificuldade na comunicação; iii) visão: incapacidade de enxergar e dificuldade em se orientar; iv) física: incapacidade de andar, desvantagem quanto a mobilidade; v) intelectual ou mental: incapacidade de aprender; vi) psicológica: incapacidade de memorização, relacionamento, desvantagem em sua integração social (AMIRALIAN et al., 2000).

Dessa forma, pode ser percebido que Amiralian et al. (2000) mencionam a incapacidade e a desvantagem. Os referidos autores explicam que a incapacidade é uma restrição que resulta em deficiência e que, por meio disso, não possível o indivíduo ter as habilidades normais de um ser humano. Já a desvantagem é um prejuízo resultante da incapacidade da pessoa com deficiência que o limita a desempenhar suas atividades de acordo com sua faixa etária, e a sua relação entre os demais indivíduos em sua vida social (AMIRALIAN et al., 2000). Mediante ao exposto, Beche (2019) argumenta que estas peculiaridades que englobam a inclusão social resultam nos maiores desafios para a inclusão das PcDs, mas que deve ser realizada em qualquer contexto social (BECHE, 2019) e organizacional (MEACHAM et al., 2017).

Alguns estudos buscaram trabalhar a inclusão social nos mais variados aspectos e contextos. O estudo de Giarè, Ricciardi e Borsotto (2019) procurou analisar a agricultura social para trabalhadores migrantes. Os resultados mostraram que a agricultura social pode ser uma resposta concreta à exploração do trabalho desempenhado pelos migrantes, sendo um caminho para promover formas inovadoras de hospitalidade, cooperativas sociais e inclusão social. Os autores enfatizam que a inclusão é o caminho para o acolhimento, principalmente aqueles que migram para uma realidade totalmente diferente da realidade de origem.

Já o estudo de Meacham et al. (2017) buscou examinar as práticas e intervenções de gestão de recursos humanos (GRH) em torno das experiências de colaboradores com deficiência intelectual. Os resultados evidenciaram a importância de práticas formais e informais de recursos humanos, como por exemplo: recrutamento e seleção inclusivos, desenvolvimento, orientação e treinamento, além de suporte diário individualizado fornecidos pelos gestores e colegas de trabalho para melhorar a participação e bemestar dos colaboradores com deficiência intelectual. Os autores, finalizam argumentando que são ações essenciais para se promover a inclusão de PcD.

O estudo de Silva, Bolson e Ferrigoti (2016) buscou avaliar as potencialidades da inclusão social em uma cooperativa no Paraná. Por meio de entrevistas, questionários e observações participantes os autores constataram que a cooperativa possui articulação entre a essência "cooperativista" e inclusão social. Os autores ainda identificaram que a inclusão social melhora as relações entre cooperados, por outro lado existe limites estruturais que podem dificultar um pouco a questão da inclusão, a saber: espaço físico, treinamento 
e outros aspectos.

Por fim, o estudo de Hammes e Nuernberg (2015) buscou mostrar a experiência vivida de trabalhadores pelo Sistema Nacional de Emprego (SINE), na cidade de Florianópolis, por meio do desenvolvimento de ações específicas para a inclusão das PcD no ambiente de trabalho. Os resultados mostraram que no desenvolver destas ações as principais dificuldades encontradas foram as barreiras atitudinais, em outras palavras, o preconceito e o desconhecimento dos indivíduos com relação à deficiência. Pode ser identificado, inclusive, a falta de rotina de fiscalização do cumprimento das cotas nas organizações. Mediante a estes resultados, os referidos autores sinalizam que o desenvolvimento de políticas públicas para as PcDs é impelido por uma transformação social. A inclusão de PcD no contexto laboral vem sendo considerada como essencial e seus reflexos são benéficos para o convívio social, num processo que busca o resgate da cidadania e o respeito dos direitos de todos os indivíduos

Ademais, o preconceito e o julgamento dos indivíduos é o que influencia para uma sociedade desumana. A deficiência muitas vezes é vista com olhos ruins e maldosos, olhos que não veem uma oportunidade de conhecimento e crescimento profissional e pessoal. Assim, todas as esferas sociais e organizacionais necessitam compreender a inclusão social, para que estas esferas sejam justas e aptas para receber as PcDs (BACHE, 2019).

\subsection{Diversidade no ambiente de trabalho}

Em 1990, nos Estados Unidos, surgem com maior frequência as discussões sobre a diversidade e somado às constantes mudanças advindas da globalização a preocupação com essa questão tem aumentado (ALVES; GALEÃO-SILVA, 2004; BARCELLOS et al., 2018). Nesse sentido, Cox (2001) define a diversidade como uma variação de identidades culturais e sociais entre os indivíduos que convivem em um mesmo sistema (social ou organizacional). O referido autor explica que a identidade desses indivíduos é explicada por meio de determinadas características, a saber: gênero, raça, nacionalidade, linguagem, idade, orientação sexual, PcDs.

A palavra diversidade é derivada do latim (diversitas) e se refere a coisas distintas, à variedade ou diferenças (FERNANDES, 2004). A diversidade se apresenta na pluralidade e singularidades de identidades que constituem um grupo ou uma sociedade (FERNANDES, 2004). O propósito da diversidade, bem como a sua gestão, consiste em administrar as relações de trabalho no sentido de reter e manter os melhores talentos, além de incluir pessoas no mercado de trabalho (FLEURY, 2000; BARCELLOS et al., 2018; MALHEIROS et al., 2020b).

Nessa perspectiva, surgem as discussões sobre a diversidade no meio organizacional. Fleury (2000) argumenta que a diversidade no ambiente de trabalho foi uma resposta à crescente diversificação da força de trabalho. Com isso, a diversidade é definida como a pluralidade de identidades de indivíduos no contexto organizacional (BAKHRI et al., 2018).

Fernandes (2004) argumenta que a existe diversos tipos de diversidade, a saber: diversidade de etnia, diversidade de raça, diversidade de orientação sexual, diversidade de linguagem, diversidade geracional, diversidade de gênero, diversidade de PcDs. Geralmente, as diversidades são percebidas por outros indivíduos no momento em que elas julgam e criam um preconceito sobre uma pessoa ou um grupo (FERNANDES, 2004; BAKHRI et al., 2018).

Nesse sentido, Baldwin, Bommer e Rubin (2015) argumentam que levando em consideração os tipos de diversidade existentes é importante entender que cada uma delas está adentrada em níveis, que correspondem ao nível superficial e o nível profundo. Os autores explicam que a diversidade de nível superficial, se refere aquelas diferenças que podem ser vistas aos olhos dos indivíduos que correspondem a características físicas: raça, gênero, idade, nacionalidade, PcDs. Já a diversidade em nível profundo representa a as diferenças que podem ser vistas ou percebidas por meio das ações dos indivíduos como por exemplo: habilidades, personalidades, conhecimento e valores.

Para Milkovich e Bodreau (2006) trabalhar com a diversidade é valorizar as relações de trabalho e incentivar a inovação e criatividade no ambiente de trabalho. Para os referidos autores, esses aspectos, melhoram não só as relações interpessoais, mas também a produtividade organizacional e a vantagem competitiva frente aos seus concorrentes. Em organizações cooperativas, da mesma forma, as relações interpessoais entre os cooperados e colaboradores são melhoradas quando se trabalha com a diversidade e se tem um meio para a inclusão destas no mercado de trabalho (PEREIRA; SANCHES, 2013). Frente a isso, Malheiros et al. (2020a) argumentam que as organizações precisam estabelecer uma cultura que fomente 0 aceite e trabalho com a diversidade.

O estudo de Barcellos et al. (2018) procuraram analisar a diversidade e a inclusão social em uma filial de uma rede de farmácias. Por meio de entrevistas semiestrutuadas, os autores constataram que a filial tem conhecimento do é a diversidade a inclusão social de uma forma limitada. Para os gestores, a inclusão social e a diversidade se resumiu apenas aos PcDs, visto que a filial de farmácia possui um programa exclusivo 
para esse tipo de diversidade.

No cenário da diversidade se apresenta as PcDs e que, constantemente, lutam para conquistar seu espaço em espaços públicos e privados, buscando por oportunidades de trabalho (SILVA et al., 2017). Assim sendo, no estudo dos referidos autores, foi buscado investigar os desafios para a inclusão de PcDs em organizações do setor de construção civil. Para a obtenção dos resultados foram aplicadas entrevistas semiestruturadas para seis gestores. Como resultado, os autores constataram diversas barreiras para a inclusão destes no setor de estudo, tais como a contratação e manutenção dos PcDs nas organizações; sendo que é um dos principais aspectos mencionados como barreiras correspondem a improdutividade, uma sensação de falsa segurança a estes colaboradores e a ausência de políticas adequadas para o grupo de PcDs.

Por fim, o estudo de Malheiros et al. (2020a) procurou analisar o papel da cultura organizacional na compreensão da diversidade. Os autores realizaram entrevistas semiestruturadas em uma indústria de cosméticos e como resultados constataram que a referida organização possui uma cultura bem definida e que proporciona aos seus colaboradores o entendimento da diversidade no ambiente de trabalho. Dessa forma, os autores concluem que a cultura organizacional é um fator importante a ser levado em consideração para se trabalhar com a diversidade.

\section{PROCEDIMENTOS METODOLÓGICOS}

A presente pesquisa é do tipo exploratória e adota uma abordagem qualitativa. Pesquisas descritivas têm como objetivo o delineamento de características de uma população, fenômenos ou fatos (MARCONI; LAKATOS, 2009). Nesse aspecto, a abordagem qualitativa se mostrou a mais adequada para este estudo, uma vez que foi buscado compreender e classificar processos dinâmicos vividos por grupos sociais, além de fornecer ricas descrições de um determinado universo (DIEHL; TATIM, 2004).

Nesse aspecto, o método utilizado para a investigação do problema foi o estudo de caso complementado por pesquisa documental. No presente estudo, especificamente, a pesquisa foi realizada na cooperativa Cotripal, localizada no munícipio de Panambi, Rio Grande do Sul. Esta organização corresponde a um dos maiores mercados cooperativos da região Norte do RS, sendo que, além da matriz localizada em Panambi, tem-se mais 5 extensões da Cotripal (outro mercado em Panambi, Condor, ljui, Pejuçara, Santa Barbara do Sul). Os serviços prestados pela cooperativa além dos mercados correspondem a: farmácias, vestuário, restaurantes, postos de gasolina, serviços agropecuários e autopeças. A organização em questão é de grande porte e se constitui como referência no meio cooperativo.

Os sujeitos participantes correspondem a uma supervisora de $\mathrm{RH}$ e 07 colaboradores com deficiência. Desses 07 colaboradores, 6 possuem deficiência mental (e.g. síndrome de down - na qual a organização caracteriza como deficiência mental) e um outro colaborador possui deficiência auditiva.

Para a coleta de dados, foi construído um roteiro semiestruturado contendo 11 perguntas que foram destinadas para a supervisora de RH. A coleta de dados dos PcDs se deu a partir de documentos da organização que continham entrevistas realizadas pelos padrinhos. Embora com limitações, essas entrevistas, na avaliação dos pesquisadores, continham dados suficientes para se realizar a análise.

A coleta de modo documental das entrevistas para as PcDs aconteceu dessa forma, pela razão de não se saber como seria o comportamento desses colaboradores com a abordagem dos pesquisadores e também não possuir vínculos com estes colaboradores, o que dificultaria ainda mais o desenvolvimento do estudo com as entrevistas feitas diretamente a eles. Na organização em questão, cada PcD possui um "padrinho" e, para realizar a entrevista, deveria ser com a presença desse padrinho. Por essa razão, optou-se por coletar esses dados por meio de entrevistas realizadas pela organização, com o auxílio dos padrinhos e publicadas na revista institucional. A supervisora concordou em disponibilizar esse material para análise e utilização do necessário para a respostas das perguntas do roteiro II de entrevista. Além disso, a gestora de RH explica que os padrinhos acompanham os PcDs no desenvolver das suas tarefas, cursos de capacitação, entre outras atividades.

Para a análise de dados, foi utilizada a categorização dos dados e a análise de conteúdo para as entrevistas semiestruturadas. Com relação aos documentos da organização, esses foram analisados por meio de uma análise documental e utilizados como forma de buscar dados que venham a valorizar os achados deste estudo (BARDIN, 2010). Dessa forma, a Figura 1 apresenta o desenho da pesquisa. 
Figura 1 - Desenho de pesquisa

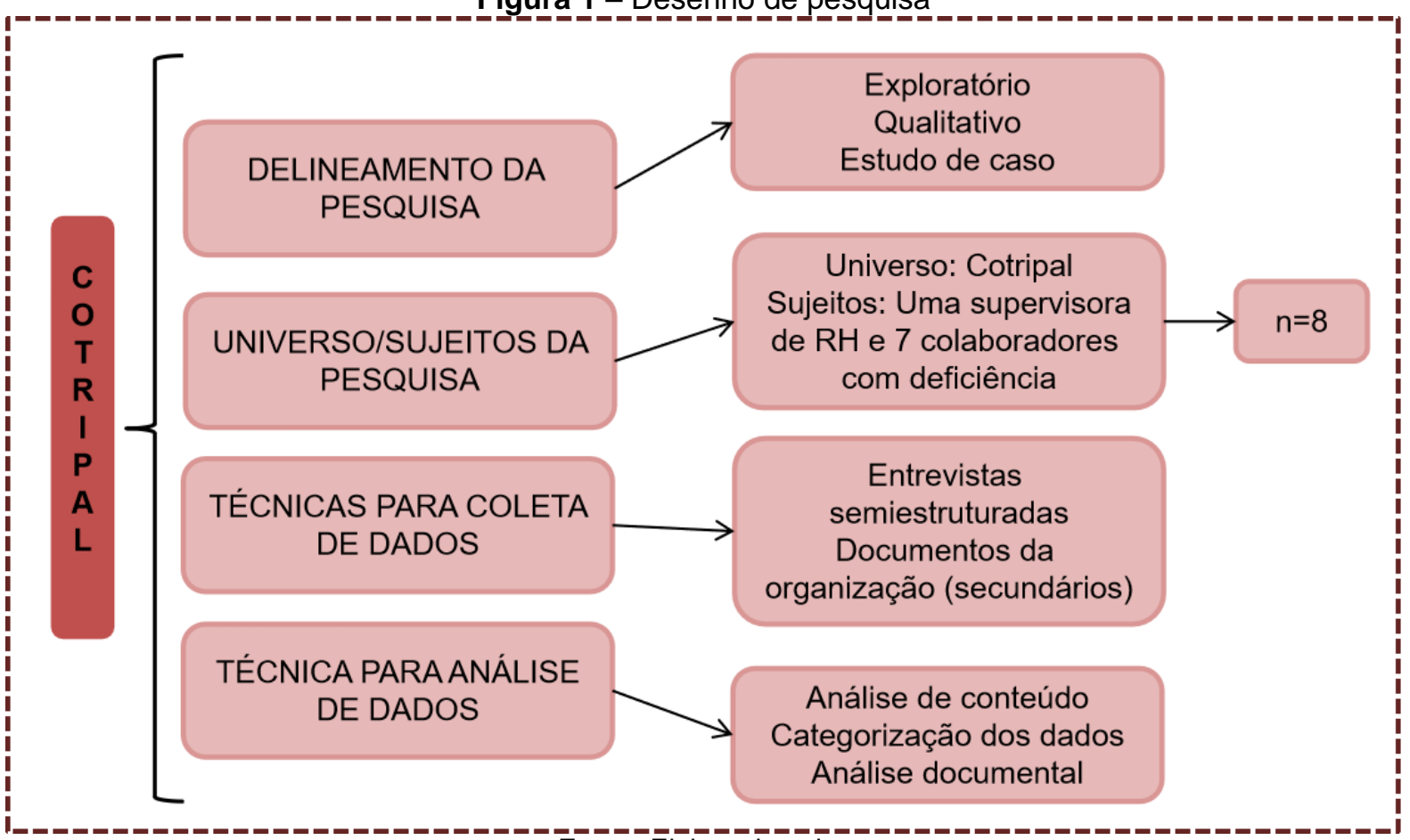

Fonte: Ėlaborado pelos autores.

No dia $1^{\circ}$ de novembro de 2017, foi realizada a entrevista aplicando o roteiro $1 \mathrm{com}$ a supervisora de $\mathrm{RH}$, a fim de abordar como a organização trabalha com a Inclusão, preparo dos colaboradores, treinamentos e o significado em ter os PcDs inclusas no seu quadro de colaboradores. O segundo roteiro foi coletado de forma documental, cujos dados de sete colaboradores foram retirados da revista Atualidades da Cotripal.

\section{ANÁLISE E DISCUSSÃO DOS RESULTADOS}

Nesta seção, são apresentados os resultados da pesquisa bem como suas discussões.

\subsection{Entrevista com a supervisora de rh}

$\mathrm{Na}$ primeira entrevista realizada com a supervisora do $\mathrm{RH}$, essa foi questionada sobre: quantos colaboradores a Cotripal possui ao todo; quantas são PcDs; quais são as deficiências desses colaboradores; como é a relação interpessoal; se o ambiente de trabalho é acessível; se estes colaboradores se enquadram em todos os setores da cooperativa; há quanto tempo é contratado as PcDs; qual critério é utilizado para direcionar uma PCD ao seu setor; como é feita a contratação e a demissão (no caso da responsabilidade contratual); se o colaborador com deficiência possui os mesmos direitos e deveres que os demais colaboradores e, por fim, o que significa para a cooperativa a contratação das PcDs.

Como mencionado na metodologia, a primeira entrevista foi realizada com a supervisora de $\mathrm{RH}$ da cooperativa. Essa colaboradora trabalha há 30 anos na organização. No Quadro 1, são expostos os resultados da entrevista com a supervisora.

Quadro 1 - Entrevista com a supervisora de RH da cooperativa

\begin{tabular}{|l|l|}
\hline \multicolumn{1}{|c|}{ RATEGORIAS } & \multicolumn{1}{c|}{ Roteiro de entrevista I } \\
\hline $\begin{array}{l}\text { Número de } \\
\text { colaboradores da } \\
\text { organização }\end{array}$ & $\begin{array}{l}\text { "A partir do último levantamento feito em 30 de setembro, a Cotripal possui 2150 } \\
\text { funcionários distribuídos em todas as unidades". }\end{array}$ \\
\hline $\begin{array}{l}\text { Número de } \\
\text { colaboradores com } \\
\text { deficiência }\end{array}$ & $\begin{array}{l}\text { "A partir do mesmo levantamento de 30 de setembro, a Cotripal possui 98 } \\
\text { pessoas com deficiências, onde 6 destas participam do sistema de aprendizagem } \\
\text { interno da cooperativa". }\end{array}$ \\
\hline $\begin{array}{l}\text { Tipos de deficiência dos } \\
\text { colaboradores }\end{array}$ & $\begin{array}{l}\text { "Dessas 98 PcDs inclusas na Cotripal, 50 delas são comprometidas intelectual e } \\
\text { mentalmente. As demais se dividem nos demais tipos de deficiências com } \\
\text { exceção da deficiência visual". }\end{array}$ \\
\hline
\end{tabular}




\begin{tabular}{|c|c|}
\hline $\begin{array}{l}\text { Relação interpessoal } \\
\text { com as PcDs }\end{array}$ & $\begin{array}{l}\text { "A Cotripal trabalha com vários projetos e aplica palestras constantemente para } \\
\text { ter uma boa convivência com essas pessoas e para que todos os colaboradores } \\
\text { possam entender que o tratamento deve ser de igual para igual. [...]. A } \\
\text { organização possui um grupo de tantas pessoas que tem a função de estudar } \\
\text { sobre deficiências, estas se especializam e trabalham para que as PcDs sejam } \\
\text { bem recebidas e tenham um bom desenvolvimento dentro da empresa [...]". }\end{array}$ \\
\hline $\begin{array}{l}\text { Ambiente de trabalho } \\
\text { acessível }\end{array}$ & $\begin{array}{l}\text { "A Cotripal tem um programa que chamam de Programa Inclusão Juntos Somos } \\
\text { MAIS, onde no momento da contratação de qualquer funcionário a Cotripal aplica } \\
\text { treinamentos e palestras para melhor receber o seu colaborador. Dentro desse } \\
\text { programa existe o Programa de Integração, onde é trabalhado os termos } \\
\text { Acessibilidade Arquitetônica e Acessibilidade Atitudinal. Na Acessibilidade } \\
\text { Arquitetônica a preocupação é com a estrutura da organização para receber as } \\
\text { PcDs, [...]. A Acessibilidade Atitudinal trata de educar os demais colaboradores } \\
\text { para que eles ajudem com as PcDs com atitudes, [...], pois assim [...] seu bem- } \\
\text { estar sempre estará em evidencia dentro da organização". }\end{array}$ \\
\hline $\begin{array}{l}\text { Enquadramento das } \\
\text { PcDs em todos os } \\
\text { setores }\end{array}$ & $\begin{array}{l}\text { "[...], a Cotripal tem em vista na hora de contratar uma PcD que a vaga se encaixa } \\
\text { a pessoa, ela se torna um colaborador pelo sistema de cotas e é feito o processo } \\
\text { de adequação da mesma em todos os setores possíveis, onde a pessoa se } \\
\text { encaixar ela exercera a função. [...]". }\end{array}$ \\
\hline $\begin{array}{l}\text { Tempo de contratação } \\
\text { das PcDs }\end{array}$ & $\begin{array}{l}\text { "A Cotripal passou a contratar pela lei de cotas a partir de } 2013 \text { onde a } \\
\text { fiscalização do ministério de trabalho passou a exigir das organizações das } \\
\text { cidades do interior do Estado do Rio Grande do Sul. [...]". }\end{array}$ \\
\hline $\begin{array}{l}\text { Critério de } \\
\text { direcionamento ao } \\
\text { cargo }\end{array}$ & $\begin{array}{l}\text { A Cotripal visa tentativas de adaptação da PcD ao cargo até que seja encontrado } \\
\text { setor certo que ela desempenhara suas funções como colaborador". }\end{array}$ \\
\hline Contratação e demissão & $\begin{array}{l}\text { CONTRATAÇÃO: "[...]. A Cotripal não abre vagas especiais para PcD, elas } \\
\text { concorrem a vaga de emprego como qualquer outra pessoa, após contratação } \\
\text { eles adaptam a vaga a pessoa contratada. Após contratação a pessoa com } \\
\text { deficiência deve apresentar laudo com CID (Código Internacional de Doenças) } \\
\text { assinado por ela mesma comprovando a aceitação de sua deficiência juntamente } \\
\text { com o ASO (Atestado de Saúde Ocupacional), esses documentos são } \\
\text { encaminhados ao Ministério do Trabalho". DEMISSÃO: "Para ocorrer uma } \\
\text { demissão, principalmente quando a organização ainda não atingiu a cota, deve- } \\
\text { se comprovar o motivo e todos os processos feitos para evitar a demissão da } \\
\text { PcD. Na Cotripal a partir do momento da contratação é feito relatos em forma de } \\
\text { um diário onde é colocado todos os passos e atitudes do colaborador. Para haver } \\
\text { uma demissão se é comprovado que foram esgotadas todas as possibilidades e } \\
\text { tentativas de manter o colaborador na empresa, essa decisão se dá com o aval } \\
\text { da família que também participa de todos os momentos e decisões para que seja } \\
\text { tomada a melhor solução sempre pensando no bem estar da PcD". }\end{array}$ \\
\hline $\begin{array}{l}\text { PcDs com mesmos } \\
\text { direitos e deveres }\end{array}$ & $\begin{array}{l}\text { "[...], a pessoa com deficiência tem os mesmos direitos e deveres que os demais } \\
\text { colaboradores dentro da Cotripal. A cooperativa não inferioriza e trata de forma } \\
\text { diferente estes colaboradores, ela tem como princípio tratar de igual para igual, } \\
\text { [...], incluir elas no mercado de trabalho para sua independência e crescimento } \\
\text { como indivíduo". }\end{array}$ \\
\hline $\begin{array}{l}\text { Significado para a } \\
\text { organização a } \\
\text { contratação de PcD }\end{array}$ & $\begin{array}{l}\text { ara a Cotripal ter uma PcD favorece a imagem corporativa da Cooperativa, } \\
\text { strando seu interesse pela comunidade, fazendo um programa com qualidade, } \\
\text { ndo referência como um ambiente que educa e proporcionando muitas vezes } \\
\text { rimeiro emprego para a pessoa inclusa". }\end{array}$ \\
\hline
\end{tabular}

Fonte: Dados da pesquisa.

Como se pode perceber, a organização apresenta um bom número de colaboradores, o que caracteriza a empresa como grande porte. Com relação aos colaboradores com deficiência, nota-se a presença de 98 indivíduos contratados formalmente. Desses 98 colaboradores, 50 deles apresentam deficiência intelectual ou mental, e os demais apresentam outro tipo de deficiência. A gestora ainda destacou que nenhum desses $\operatorname{PcD}$ apresenta deficiência visual. Nota-se que a organização ainda não tem todas cotas preenchidas, sendo que $4,56 \%$ das vagas estão sendo usadas e o recomendado pela lei é $5 \%$.

Com relação ao relacionamento interpessoal com esses colaboradores, nota-se que flui de modo saudável, em que é procurado priorizar o bem-estar dos indivíduos. Essa preocupação fica ainda mais evidente com a realização de projetos e palestras para que as PcDs tenham tratamento justo e seus colegas 
de trabalho estejam conscientes da sua condição e importância no meio laboral. Levando em consideração estes relatos, em 1824, no Brasil, foi estruturada a Carta Magna, que considerava as PcDs como "incapazes" e não tinham direitos garantidos (WALLERIUS; BISSANI, 20115). Segundo os referidos autores, foi, somente a partir da Constituição Federal de 1988, que as PcDs tiveram seus direitos reconhecidos de modo mais evidente e, desde então, a evolução, no contexto de trabalho para a contratação de colaboradores com deficiência. é muito expressiva.

No que diz respeito ao direcionamento para um cargo na cooperativa, a entrevistada relatou que as PcDs vão passando pelos setores até que um desses seja considerado como os mais adequados para o colaborador. Segundo Nepomuceno e Carvalho-Freitas (2008), é fundamental que o indivíduo tenha a percepção adequada para o direcionamento a um cargo dentro de uma organização. As referidas autoras explicam que essas percepções se configuram como: percepção de desempenho, percepção de vínculo, percepção dos benefícios da contratação e percepção de necessidade de treinamento (LO; HE; LIU, 2019). Dessa forma, conforme os relatos da entrevistada, essas percepções são possibilitadas para os PcDs, sendo que no setor ou cargo que este melhor se identifica passa a ser o seu local e/ou cargo de trabalho.

$\mathrm{Na}$ categoria de contratação, direitos e deveres, a entrevista relatou que todos possuem os mesmos direitos e deveres, na qual o objetivo da contratação das PcDs é favorecer o crescimento pessoal e profissional desses colaboradores, que tenham a sua independência, assim como os demais. A única diferença refere-se à contratação, em que a $\operatorname{PcD}$ deve apresentar um documento que comprove sua deficiência. No que tange à demissão, é feito todo o esforço para que as PcDs se mantenham na organização e essa etapa seja evitada. Na visão de Wallerius e Bissani (2015), essa atitude corresponde a um ato para além da inclusão, é um ato de cidadania.

Por fim, quando perguntado sobre a importância para a organização, a contratação das PcDs, a entrevistada relatou que essa atitude favoreceu a imagem corporativa, tornando-se como referência para outras organizações. Labbé et al. (2020) argumentam que organizações socialmente responsáveis despertam o interesse das pessoas na organização. Indiscutivelmente, percebe-se que a organização é bem estruturada e que o início da contratação de colaboradores, com algum tipo de deficiência, só se tornou realidade com a existência da Lei de Cotas. Dessa forma, parece haver uma linha tênue no que diz respeito à "inclusão" e à "inserção", ou seja, ao mesmo tempo em que a organização parece somente "cumprir" uma lei e inserir PcDs, dedica esforços para manter esses colaboradores no seu quadro de funcionários e trabalha, constantemente, para que o bem-estar desses colaboradores seja garantido.

\subsection{CARACTERIZAÇÃO DOS PARTICIPANTES}

Primeiramente, no Quadro 2, apresenta-se a caracterização do perfil dos colaboradores. Com a intenção de proteger a identidade desses, para cada um dos participantes da pesquisa, foram adotados nomes fictícios.

Quadro 2 - Caracterização do perfil dos colaboradores com deficiência

\begin{tabular}{|c|c|c|c|c|}
\hline COLABORADOR & SEXO & IDADE & CARGO/FUNÇÃo & TIPO DE \\
DEFICIÊNCIA \\
\hline TRAB1 & Feminino & 37 anos & $\begin{array}{c}\text { Repositora/Loja de } \\
\text { Confecções }\end{array}$ & Auditiva \\
\hline TRAB2 & Feminino & 24 anos & $\begin{array}{c}\text { Garçonete/Restaurante } \\
\text { Supermercado }\end{array}$ & Mental \\
\hline TRAB3 & Feminino & 30 anos & Auxiliar de RH & Mental \\
\hline TRAB4 & Masculino & 38 anos & Empacotador & Mental \\
\hline TRAB5 & Masculino & 18 anos & Auxiliar de depósito & Mental \\
\hline TRAB6 & Masculino & 23 anos & Repositor & Mental \\
\hline TRAB7 & Masculino & 20 anos & Conferente/Farmácia & Mental \\
\hline
\end{tabular}

Fonte: Dados da pesquisa.

Como se pode perceber no Quadro 2, a maioria dos colaboradores participantes desse estudo 4 são do sexo masculino e 3 do sexo feminino. Com relação a idade desses, tem-se uma variação entre 18 a 38 anos, sendo que o TRAB5 é o colaborador com deficiência mais jovem. Pela razão da Cotripal atuar em diversos setores, esses colaboradores estão distribuídos em diversas funções e locais de trabalho.

Assim sendo, a TRAB 1 exerce a função de repositora na loja de confecções da cooperativa. A TRAB2 tem a função de garçonete no restaurante do mercado. É importante salientar que a loja de confecções e o restaurante são anexos ao mercado na sede matriz da Cotripal em Panambi. Por sua vez, a TRAB3 desempenha a função de auxiliar de RH. O TRAB4 desempenha a função de empacotador. Já o TRAB5 trabalha como auxiliar de depósito do mercado. Já o TRAB6 é repositor de mercadorias diversas. Por fim, o 
TRAB7 é conferente na farmácia da Cotripal. A farmácia é anexa ao posto de gasolina, também localizada em Panambi, em frente ao mercado sede.

\subsection{ANÁLISE DAS ENTREVISTAS COM OS PADRINHOS}

Nesta seção, são apresentados os dados obtidos (de forma documental) nas entrevistas aos colaboradores com deficiência, dadas em uma edição da revista da organização. Considerando a quantidade de informações obtidas, estruturou-se o Quadro 3 e Quadro 4, com todos os relatos obtidos. É importante salientar que esses dados foram coletados de modo documental e todas as respostas contidas, nesses dados, tiveram o suporte dos padrinhos das PcDs.

Quadro 3 - Entrevistas entre padrinhos e colaboradores

\begin{tabular}{|c|c|c|c|}
\hline CATEGORIAS & $\begin{array}{l}\text { TRAB1 } \\
\end{array}$ & TRAB2 & TRAB3 \\
\hline $\begin{array}{l}\text { Tempo que está no } \\
\text { mercado de } \\
\text { trabalho }\end{array}$ & $\begin{array}{l}\text { Um pouco mais de um ano. Na } \\
\text { Cotripal, foi seu primeiro emprego. }\end{array}$ & $\begin{array}{l}\text { "Trabalhava com sua tia duas vezes } \\
\text { por semana. Mas seu trabalho formal } \\
\text { se iniciou com a Cotripal há três } \\
\text { anos". }\end{array}$ & $\begin{array}{l}\text { "Antes da Cotripal, trabalhou no } \\
\text { comércio de Panambi, mas por } \\
\text { pouco tempo". }\end{array}$ \\
\hline $\begin{array}{l}\text { Descrição do cargo } \\
\text { ocupado/função } \\
\text { desempenhada }\end{array}$ & $\begin{array}{l}\text { "[...] monitora as roupas após } \\
\text { serem provadas, ajudando na } \\
\text { organização dos cabides, [...]. } \\
\text { Também auxilia os colegas no } \\
\text { depósito sempre que é preciso. Ela } \\
\text { conta que gosta de todas as } \\
\text { atividades que realiza, mas } \\
\text { principalmente, de ver as coisas } \\
\text { arrumadas em seus devidos } \\
\text { lugares". }\end{array}$ & $\begin{array}{l}\text { "[...], suas atividades são organizar } \\
\text { as bandejas e ajudar a recolher os } \\
\text { pratos, mas o que mais gosta é } \\
\text { higienizar os talheres e as taças de } \\
\text { sobremesa". }\end{array}$ & $\begin{array}{l}\text { "[...] Entre suas atividades } \\
\text { preferidas estão organizar } \\
\text { arquivos, preparar materiais para } \\
\text { cursos, fazer serviços e levar } \\
\begin{array}{l}\text { documentos para outros } \\
\text { departamentos". }\end{array}\end{array}$ \\
\hline $\begin{array}{l}\text { Como ingressou no } \\
\text { mercado de } \\
\text { trabalho }\end{array}$ & $\begin{array}{l}\text { "A diretora da APAE de Panambi, } \\
\text { [...], percebeu que a jovem poderia } \\
\text { crescer muito no mercado de } \\
\text { trabalho, e pediu que a família } \\
\text { enviasse um currículo para a } \\
\text { Cotripal.[...], foi contratada e ficou } \\
\text { muito feliz com o setor para o qual } \\
\text { foi destinada". }\end{array}$ & $\begin{array}{l}\text { "Em novembro de 2013, com o } \\
\text { incentivo da professora, que a } \\
\text { acompanhou na primeira entrevista, } \\
\text { iniciou-se o processo de inserção [...] } \\
\text { no mercado de trabalho". }\end{array}$ & $\begin{array}{l}\text { "Sua mãe procurou a cooperativa } \\
\text { para pedir emprego". }\end{array}$ \\
\hline Destino da renda & $\begin{array}{l}\text { "[...] ajuda os pais a pagar água e } \\
\text { luz, além de comprar algumas } \\
\text { guloseimas no mercado, como } \\
\text { salgadinho de milho. Outra parte } \\
\text { do seu salário é guardada para o } \\
\text { futuro, e uma terceira parte está } \\
\text { reservada para a sonhada viagem } \\
\text { para Recife". }\end{array}$ & $\begin{array}{l}\text { "[...],compra guloseimas no } \\
\text { Supermercado, } \quad \text { mas por } \\
\text { recomendações médicas não come } \\
\text { tudo que gostaria. Outra parte guarda } \\
\text { na poupança, e ainda ajuda a pagar } \\
\text { as contas mensais, como água e luz". }\end{array}$ & $\begin{array}{l}\text { "Foi com o próprio dinheiro } \\
\text { também que ela reformou o quarto } \\
\text { e o banheiro, na casa onde mora } \\
\text { com os pais. [...]. "Eu tive que } \\
\text { economizar bastante para realizar } \\
\text { este sonho e estou muito feliz e } \\
\text { satisfeita. Meu quarto é meu } \\
\text { mundo". }\end{array}$ \\
\hline $\begin{array}{l}\text { Significado para a } \\
\text { organização tê-la(o) } \\
\text { como } \\
\text { colaborador(a) }\end{array}$ & $\begin{array}{l}\text { "[...] Ela é muito inteligente, } \\
\text { organizada e responsável. Nunca } \\
\text { se atrasa para o trabalho, está } \\
\text { sempre disposta e pronta para } \\
\text { ajudar. Carismática, querida e } \\
\text { alegre, ela conquista todos que a } \\
\text { conhecem. É muito bom tê-la ao } \\
\text { nosso lado aqui no setor". }\end{array}$ & $\begin{array}{l}\text { "[...]é caprichosa, dedicada e } \\
\text { disposta para aprender. [...], ela é } \\
\text { humilde para aceitar as explicações e } \\
\text { mudar suas atitudes. Os } \\
\text { treinamentos que recebemos do RH e } \\
\text { o incentivo da família foram } \\
\text { fundamentais para que ela se } \\
\text { desenvolvesse tão bem, e } \\
\text { certamente ainda terá muito sucesso } \\
\text { na vida. Ela é querida por todos os } \\
\text { colegas [...]". }\end{array}$ & $\begin{array}{l}\text { "[...], é uma colaboradora } \\
\text { dedicada e vemos sua evolução } \\
\text { diariamente. Quando começou } \\
\text { não sabíamos até onde ela } \\
\text { conseguiria evoluir, [...] nos } \\
\text { surpreende a todo o momento, } \\
\text { aumentando conquistas. Para a } \\
\text { equipe do RH, é uma satisfação tê- } \\
\text { la como colega, pois ensinamos } \\
\text { muitas coisas a ela, mas também } \\
\text { aprendemos com sua dedicação } \\
\text { [...]". }\end{array}$ \\
\hline Visão para o futuro & $\begin{array}{l}\text { "[...]sonha em casar e comprar um } \\
\text { carro, além de poder viajar e } \\
\text { conhecer outros lugares do mundo. }\end{array}$ & $\begin{array}{l}\text { "[...] Ter um trabalho todos os dias, } \\
\text { salário certinho e poder ajudar minha } \\
\text { família são conquistas que tive nos } \\
\text { três últimos anos. "E sei que ainda } \\
\text { tenho muitas coisas para conquistar". }\end{array}$ & Essa pergunta não foi respondida. \\
\hline
\end{tabular}

Fonte: Dados da pesquisa. 


\begin{tabular}{|c|c|c|c|c|}
\hline CATEGORIAS & TRAB4 & TRAB5 & TRAB6 & TRAB7 \\
\hline $\begin{array}{l}\text { Tempo que está no } \\
\text { mercado de } \\
\text { trabalho }\end{array}$ & $\begin{array}{l}\text { "[...].Ele se formou pelo } \\
\text { SENAI (Serviço Nacional } \\
\text { de Aprendizagem } \\
\text { Industrial), no técnico em } \\
\text { Logística, mas a empresa } \\
\text { onde realizou o estágio } \\
\text { final não tinha vaga para } \\
\text { mantê-lor como } \\
\text { colaborador". }\end{array}$ & $\begin{array}{l}\text { "Na Cotripal foi seu } \\
\text { primeiro emprego, iniciou } \\
\text { suas atividades há dois } \\
\text { anos". }\end{array}$ & $\begin{array}{l}\text { "A Cotripal foi seu primeiro } \\
\text { emprego, iniciou duas } \\
\text { atividades há quatro } \\
\text { anos". }\end{array}$ & $\begin{array}{l}\text { "A Cotripal foi seu } \\
\text { primeiro emprego". }\end{array}$ \\
\hline $\begin{array}{l}\text { Descrição do cargo } \\
\text { ocupado/função } \\
\text { desempenhada }\end{array}$ & $\begin{array}{l}\text { "[...].A atividade que o } \\
\text { colaborador mais gosta de } \\
\text { realizar é recolher } \\
\text { carrinhos e cestinhos e } \\
\text { organizá-los". }\end{array}$ & $\begin{array}{l}\text { "[...],organizar } \\
\text { mercadorias, separar } \\
\text { pedidos, montar paletes } \\
\text { com produtos e auxiliar os } \\
\text { colegas quando solicitado". }\end{array}$ & $\begin{array}{l}\text { "[...]. } \text { Repõem produtos } \\
\text { nas prateleiras, verifica } \\
\text { códigos, quantidades e } \\
\text { validades". }\end{array}$ & $\begin{array}{l}\text { "[...]. Fazer a conferência } \\
\text { de medicamentos, o } \\
\text { trabalho exige certo } \\
\text { conhecimento de nomes, } \\
\text { substâncias, laboratórios } \\
\text { e notas fiscais". }\end{array}$ \\
\hline $\begin{array}{l}\text { Como ingressou no } \\
\text { mercado de } \\
\text { trabalho }\end{array}$ & $\begin{array}{l}\text { "A família soube das vagas } \\
\text { para pessoas com } \\
\text { deficiência na Cooperativa } \\
\text { por intermédio da APAE } \\
\text { Panambi e logo procurou o } \\
\text { departamento de RH". }\end{array}$ & $\begin{array}{l}\text { "[...]Seus avós em uma } \\
\text { conversa com uma caixa } \\
\text { do supermercado ficara } \\
\text { sabendo que a Cotripal } \\
\text { tinha vagas e naquele } \\
\text { momento foram atrás do } \\
\text { RH". }\end{array}$ & $\begin{array}{l}\text { "[...] falou ao seu pai no } \\
\text { interesse em conseguir } \\
\text { seu primeiro emprego. O } \\
\text { pai que já foi funcionário } \\
\text { da Cotripal procurou o } \\
\text { departamento de RH para } \\
\text { ver se havia uma } \\
\text { oportunidade [...]". }\end{array}$ & $\begin{array}{l}\text { "[...] deixou currículo em } \\
\text { diversas empresas de } \\
\text { Panambi que nunca o } \\
\text { chamaram. Até o dia que } \\
\text { decidiu ir à Cotripal e } \\
\text { ocorreu tudo certo e logo } \\
\text { foi contratado". }\end{array}$ \\
\hline Destino da renda & $\begin{array}{l}\text { "Viajar para as praias de } \\
\text { Santa Catarina é o sonho } \\
\text { dele, que está guardando } \\
\text { um pouco do seu salário } \\
\text { para, nas férias, visitar o } \\
\text { estado vizinho com a } \\
\text { família". }\end{array}$ & $\begin{array}{l}\text { "Compra suas coisas, já } \\
\text { comprou um celular novo e } \\
\text { agora está guardando } \\
\text { dinheiro para fazer sua } \\
\text { habilitação para moto e } \\
\text { carro". }\end{array}$ & $\begin{array}{l}\text { "Investe nele e no negócio } \\
\text { que tem com seu pai". }\end{array}$ & $\begin{array}{l}\text { "[...],. ter um salário o } \\
\text { ajuda a ser mais } \\
\text { independente e poder } \\
\text { comprar o que gosta. Já } \\
\text { tirou carteira de motorista } \\
\text { e comprou seu carro". }\end{array}$ \\
\hline $\begin{array}{l}\text { Significado para a } \\
\text { organização tê- } \\
\text { lá(o) como } \\
\text { colaborador (a) }\end{array}$ & $\begin{array}{l}\text { "[...]é comprometido, } \\
\text { pontual, trabalha muito } \\
\text { bem, está sempre atento } \\
\text { ao ambiente, conhece } \\
\text { todos os colegas pelo } \\
\text { nome e faz questão de } \\
\text { cumprimentá-los. [...]. }\end{array}$ & $\begin{array}{l}\text { "[...] A equipe que atua } \\
\text { aqui sentou, conversou e } \\
\text { se organizou para recebê- } \\
\text { lo. Com pequenos ajustes } \\
\text { e algumas conversas, ele } \\
\text { se adaptou às atividades e } \\
\text { as desempenha com } \\
\text { cuidado e atenção. É um } \\
\text { colaborador muito bom, } \\
\text { que está sempre disposto a } \\
\text { ajudar. Além disso, desde } \\
\text { que chegou sua } \\
\text { capacidade de aprender e } \\
\text { gravar atividades } \\
\text { aumentou o que amplia } \\
\text { suas possibilidades de } \\
\text { atuação". }\end{array}$ & $\begin{array}{l}\text { "[...] trabalha de forma } \\
\text { tranquila, é organizado, } \\
\text { desempenha r suas } \\
\text { funções com excelência. } \\
\text { Ele tem um bom } \\
\text { relacionamento } \\
\text { todos, [...], hoje é outra } \\
\text { pessoa que está aqui, } \\
\text { mais desinibido e alegre. É } \\
\text { uma satisfação ter ele em } \\
\text { nossa equipe". }\end{array}$ & $\begin{array}{l}\text { "[...], toda a equipe se } \\
\text { sentiu desafiada e } \\
\text { preocupada de diversas } \\
\text { maneiras. Deixamos ele } \\
\text { tranquilo de que poderia } \\
\text { falar das dificuldades que } \\
\text { procuraríamos soluções. } \\
\text { Hoje, o Marcelo faz parte } \\
\text { da equipe, está } \\
\text { totalmente integrado, } \\
\text { tanto nas atividades do } \\
\text { dia a dia como nos } \\
\text { momentos de } \\
\text { descontração [...]". }\end{array}$ \\
\hline Visão para o futuro & $\begin{array}{l}\text { Essa pergunta não foi } \\
\text { respondida. }\end{array}$ & $\begin{array}{l}\text { Essa pergunta não foi } \\
\text { respondida. }\end{array}$ & $\begin{array}{l}\text { "[...] conciliar a carreira na } \\
\text { Cotripal com a vida de } \\
\text { apicultor. "Com as duas, } \\
\text { minha vida fica completa". }\end{array}$ & $\begin{array}{l}\text { "[...]continuar estudando } \\
\text { e trabalhando na } \\
\text { Cotripal". }\end{array}$ \\
\hline
\end{tabular}

Fonte: Dados da pesquisa.

Com base nos dados expostos no Quadro 3 e 4, pode-se perceber que a maioria dos colaboradores teve como primeiro emprego a Cotripal, e pouco deles teve alguma experiência profissional anteriormente. Todos souberam das oportunidades de emprego na organização por meio de um outro colaborador ou de alguém que conhecia a Cotripal. Mediante as funções que exercem, percebe-se que todos os colaboradores gostam do que fazem e se sentem felizes com o seu papel mediante a organização.

Com relação a isso, a TRAB1 relata que "Também auxilia os colegas no depósito sempre que é preciso", ou seja, ela desempenha uma atividade extra. Segundo Organ (2018), essa atividade extra é caracterizada como comportamento de cidadania organizacional, na qual o indivíduo desempenha uma função que não está prescrita no seu contrato formal de trabalho. Segundo o referido autor, essas funções extras são desempenhadas de modo voluntário, sem que isso seja uma obrigação. Com base em todos os relatos, percebe-se que todos os colaboradores da organização possuem vontade de cooperar e, como ressaltaram Bateman e Organ (1983), os atos cooperativos são benéficos não só para a organização, mas também para os indivíduos.

Quanto ao salário recebido, a maioria dos entrevistados guarda uma parte em uma poupança e outra parte investe em suas necessidades e desejos pessoais. A TRAB 1 e TRAB2 ajudam a pagar a conta de água e luz na casa dos pais. O TRAB 3 conseguiu realizar o sonho de reformar seu quarto e banheiro, que, em 
suas palavras, "Meu quarto é meu mundo". A TRAB 4 e o TRAB5 conseguem comprar suas coisas, como celular, e guardar dinheiro para passar as férias na praia. Ainda, o TRAB5 e o TRAB6 já tiraram sua carteira de motorista. Desse modo, como se pode perceber, os colaboradores adquiriram a sua independência financeira e, claramente, por meio de suas falas, é notório como ter esse emprego os deixam felizes e realizados. Segundo Lara (2013), a deficiência de um indivíduo não o impede de levar uma vida cheia de realizações e de conquistas. É citado, ainda, como os pais dos colaboradores ficam felizes com as vitórias dos seus filhos.

Para a organização em questão, percebe-se que a inclusão das PcDs é uma conquista, principalmente, para quem trabalha, diretamente, com os colaboradores. Isso fica notório com base nos relatos dos padrinhos, na qual todos ressaltam diversas qualidades e características singulares do trabalho de cada um, como, por exemplo: TRAB1 - inteligente, organizada, responsável; TRAB2 - caprichosa, dedicada, disposta a ajudar; TRAB3 - dedicada; TRAB4 - comprometido e pontual; TRAB5 - disposto a ajudar; TRAB6 - organizado e eficaz; TRAB7 - parte da equipe. Dessa forma, é notório que todos os colaboradores estão integrados às suas funções e ao meio de trabalho, uma vez que a adaptação e inclusão podem ser processos difíceis para toda a organização. Os padrinhos ainda argumentam que tiveram preocupação em como trabalhar com as PcDs e como seus colegas de trabalho lidariam com essa questão. Para a felicidade de todos, essa parte foi bem trabalhada e teve êxito na organização, como se pode analisar no relato do padrinho do TRAB7: "toda a equipe se sentiu desafiada e preocupada de diversas maneiras. Deixamos ele tranquilo de que poderia falar das dificuldades que procuraríamos soluções". Os relatos dos padrinhos dos colaboradores TRAB2 e TRAB6 deixam explícito o resultado da preocupação da Cotripal no bem-estar dos seus colaboradores com deficiência: "Os treinamentos que recebemos do $\mathrm{RH}$ e o incentivo da família foram fundamentais para que ela se desenvolvesse tão bem, e certamente ainda terá muito sucesso na vida. Ela é querida por todos os colegas [...]" (TRAB2); "É uma satisfação ter ele em nossa equipe" (TRAB6).

Nesse sentido, é notória a felicidade e a satisfação de toda equipe em trabalhar com esses colaboradores. Com a inclusão, o aprendizado é diário, cada tipo de deficiência deve ter um acompanhamento, mas um dos maiores desafios é que todos os setores consigam se comunicar. Muitas vezes, os pais são superprotetores e acabam retraindo o desenvolvimento das PcDs referentes à inclusão. $A$ inclusão faz com que os colaboradores ganhem amadurecimento e saibam lidar com as diferenças, é muito importante este processo tanto para a organização quanto para as PcDs (SOUZA et al., 2017).

Como mencionado pela supervisora de RH da cooperativa, a inclusão das PcDs deu-se, somente, a partir de 2013, com a necessidade de cumprimento da Lei de Cotas. Num primeiro momento, o objetivo foi de preencher as cotas previstas em lei. Desde então, a referida cooperativa passou a adotar a contratação de colaboradores com deficiência como algo natural, sendo que as competências passaram a ganhar mais destaque do que a condição do indivíduo. Mas essa não é a realidade de diversas organizações como apontado em um estudo realizado por Souza et al. (2019) em uma cooperativa. Os autores constataram que a principal barreira para a organização se tornar inteiramente inclusiva reside na visão distorcida que os gestores apresentaram sobre inclusão. Uma vez que, como as diferenças, na maioria das vezes, são negadas, os colaboradores com deficiência perdem a oportunidade de ter suas necessidades pessoais atendidas.

Por meio dos relatos dos entrevistados, é possível identificar uma "conexão" para com a organização. Isso fica ainda mais evidente no relato do TRAB7, que sua visão de futuro é "continuar a trabalhar na Cotripal". Essa conexão é essencial para que qualquer colaborador possa desempenhar suas atividades com êxito.

Com relação à visão de futuro das PcDs, continuar trabalhando é a intenção do TRAB6 e TRAB7. Alguns entrevistados não responderam a essa pergunta. A TRAB1 sonha em casar e viajar para outros lugares mundo. A TRAB2 se vê trabalhando, pois sabe que tem muitas coisas para conquistar, conforme a própria relatou. Para as $\mathrm{PcDs}$, ter um trabalho significa independência e liberdade e, por meio do emprego, eles conhecem mais pessoas, passam por processos de socialização, contato diário, aprendizado, novas amizades, entre outros. Tais aspectos melhoram o desenvolvimento do colaborador com deficiência e contribuem muito para o seu crescimento pessoal e profissional, pois sentem que são capazes e têm a oportunidade de mostrar isso para uma organização e sua família (LABBÉ et al., 2020). No próximo item, apresentam-se dados secundários obtidos por meio de documentos da organização sobre as ações desenvolvidas pela cooperativa.

\subsection{Ações para inclusão social na organização}

Para receber os colaboradores por meio da Lei de Cotas, a Cotripal buscou contratar, também, profissionais adequados para formação de uma equipe de apoio para guiar as PcDs. Esses contratados ajudam a receber e acompanhar toda a trajetória do colaborador com deficiência, sendo que estes realizam palestras de conscientização para toda a organização compreender o que é inclusão e o que significa a contratação das PcDs. De modo mais específico, as ações realizadas na Cotripal, para bem receber as PcDs 
e mantê-las na organização, têm-se o Programa Inclusão Juntos Somos Mais. Dentro desse programa, existe, também, o Programa Inclusão que busca educar e buscar o respeito para todos os colaboradores, na qual são abordados os temas de Acessibilidade Arquitetônica e Acessibilidade Atitudinal.

$\mathrm{Na}$ Acessibilidade Arquitetônica, são abordados os assuntos pertinentes à estrutura necessária da organização para receber as PcDs e na Acessibilidade Atitudinal, é tratado da educação dos colaboradores no convívio diário com as PcDs, prestando toda ajuda necessária para bem recebê-los visando o bem-estar destes na organização.

A organização não oferta vagas específicas para as $\mathrm{PcDs}$, sendo que as vagas são abertas para todos de modo igual para todos os setores. A PcD passa por todos os processos de seleção, sendo contratado pelo sistema de cotas. A Cotripal trabalha desse modo, pois acredita que as PcDs não devem ser discriminadas pela sua deficiência e que as condições devem estar adaptadas para melhor recebê-los.

\section{CONSIDERAÇÕES FINAIS}

O objetivo deste estudo foi o de analisar a inclusão social na Cotripal em Panambi, Rio Grande do Sul. Por meio dos resultados, pode perceber que a organização se preocupa com a responsabilidade social e com a imagem que apresenta para a sociedade. Mediante isso e somado à literatura existente, é notório que as oportunidades cresceram para as PcDs. Todavia, tal constatação é fundamentada pela Lei das Cotas. Diversas PcDs estão alocadas no mercado trabalho pela obrigatoriedade da Lei $n^{\circ}=8.213 / 91$, Art 93. Vale ressaltar que, além disso, diversas organizações adotam a contratação das PcDs como algo natural e necessário que perpassa o exigido pela Lei.

O presente estudo buscou trazer relatos dos PcDs que trabalham na organização. Por mais que esses relatos tenham sido obtidos de forma documental, pois não foi permitido o contato direto com esses, foi possível verificar que os PcDs puderam expressar como se sentem tendo emprego e o que isso significa para eles. A inclusão social perpassa a esfera da obrigatoriedade, trazendo resultados positivos para toda a organização. Mais importante ainda é que, para as PcDs, ter um trabalho é algo importante e significativo. Por meio disso, eles conquistaram sua liberdade e puderam realizar alguns de seus desejos. A inclusão é importante para trazer benefícios para os dois lados.

De modo prático, os achados desta pesquisa proporcionam novas ideias de ações de inclusão que podem ser incluídas e estudadas por gestores e colaboradores, além de contribuírem ainda mais para o entendimento e para a importância de uma ação tão importante, não só para a organização em si, mas também para diversas pessoas.

Este estudo apresenta como limitação o fato de as entrevistas não terem sido feitas, diretamente, com as PcDs, Por isso, sugere-se para futuras pesquisas a realização de entrevistas que englobem um número maior de colaboradores com deficiência e que ocorram em local que não seja o da empresa. Dessa forma, será possível conseguir um panorama mais amplo e específico sobre o assunto, assim como será possível fazer um comparativo entre as percepções, conferindo maior fidedignidade aos achados.

\section{REFERÊNCIAS}

ALVES, C.; GALEÃO-SILVA, L. G. A crítica da gestão da diversidade nas organizações. Revista de Administração de Empresas, v. 44, n. 3, p. 20-29, 2004.

AMIRALIAN, M. Conceituando deficiência. Revista de Saúde Pública, v. 34, n. 1, p. 97-103, 2000. http://doi.org/10.1590/S0034-89102000000100017.

ARAUJO, A. T. Estudo da inserção de pessoas portadoras de necessidades especiais no mercado de trabalho. Caderno Profissional de Administração da UNIMEP, v. 2, n. 1, p. 20-33, 2012. Disponível em: http://www.cadtecmpa.com.br/ojs/index.php/httpwwwcadtecmpacombrojsindexphp/article/view/9/21.

ASHMOS, D. P.; DUCHON, D. Spirituality at Work: A Conceptualization and Measure. Journal of Management Inquiry, v. 9, n. 2, p. 134-46, 2000. https://doi.org/10.1177/105649260092008.

BACHE, C. Challenges to economic integration and social inclusion of Syrian refugees in Turkey. Career Development International, v. 25, p. 14-18, 2019. https://doi.org/10.1108/CDI-11-2018-0277.

BAKHRI, S. et al. Diversity Management and Organizational Culture: Literature Review, Theoretical Perspectives, and Future Directions. International Journal of Civil Engineering and Technology, v. 9, n. 1, p. 172-178, 2018.

BALDWIN, T. T.; BOMMER, W. H.; RUBIN, R. S. Gerenciando o comportamento organizacional: o que os gestores sabem e fazem. 2. ed. Rio de Janeiro: Elservier, 2015.

BARDIN, L. Análise de conteúdo. 4. ed. Lisboa: Edições70, 2010.

BARCELLOS, J. et al. Diversidade nas organizações e inclusão social: Estudo de caso em filial de uma rede de farmácia. In: 7ํFórum Internacional Ecoinovar, Santa Maria, Anais... Santa Maria: ECOINOVAR, 2018. 
BATEMAN, T. S.; ORGAN, D. W. Job satisfaction and the good soldier: the relationship between affect and employee —citizenship. Academy of Management Journal, v. 26, n. 4, p. 587-595, 1983. https://doi.org/10.2307/255908.

BRASIL. Lei no 8213/91, de 24 de julho de 1991. Lei de Contratação de Deficientes nas Empresas. Brasília, DF, 1991. Disponível em: http://www.planalto.gov.br/ccivil 03/leis//8213compilado.htm.

CAMARA, A. L. Direitos trabalhistas das pessoas portadoras de deficiência. Interface - Revista do Centro de Ciências Sociais Aplicadas, v. 1, n. 1, p. 65-76, 2004. Disponível: https://ojs.ccsa.ufrn.br/index.php/interface/article/view/14

COX, T., Jr. Creating the multicultural organization: a strategy for capturing the power of diversity. San Francisco: Jossey-Bass, 2001.

DIEHL, A. A.; TATIM, D. C. Pesquisa em ciências sociais: métodos e técnicas. São Paulo: Prentice Hall, 2004.

FERNANDES, I. A questão da diversidade da condição humana na sociedade. Revista da ADPPUCRS, n. 5, p.77-86, 2004.

FLEURY, M. T. L. Gerenciando a diversidade cultural: experiência de empresas brasileiras. Revista de Administração de Empresas, v. 40, n. 3, p. 18-25, 2000. http://doi.org/10.1590/S0034-75902000000300003.

GHIRARDI, M. I. G. Trabalho e deficiência: as cooperativas como estratégia de inclusão social. Revista de Terapia Ocupacional da Universidade de São Paulo, v. 14, n. 2, p. 49-54, 2004.

GIARÈ, F.; RICCIARDI, G.; BORSOTTO, P. Migrants Workers and Processes of Social Inclusion in Italy: The Possibilities Offered by Social Farming. Sustainability, v. 12, p. 1-20, 2019. https://doi.org/10.3390/su12103991.

GIOVANNINNI, M. What gets measured gets done. The Journal for Quality \& Participation, p. 21-27, 2004. Disponível em: https://www.yourhomeworksolutions.com/wp-content/uploads/edd/2017/06/what get mesaured 0.pdf.

HAMMES, I. C.; NUERNBERG, A. H. A Inclusão de Pessoas com Deficiência no Contexto do Trabalho em Florianópolis: relato de experiência no sistema nacional de emprego. Psicologia: Ciência e Profissão, v. 35, n. 3, p. 768-780, 2015. http://doi.org/10.1590/1982-3703000212012.

LABBÉ, D. et al. Using photovoice to increase social inclusion of people with disabilities: Reflections on the benefits and challenges. Journal of Community Psychology, edição especial, p. 1-14, 2020. https://doi.org/10.1002/jcop.22354.

LARA, L. F. A gestão de pessoas e o desafio da inclusão das pessoas com deficiência: uma visão antropológica da deficiência. Revista Capital Científico, v. 11, n. 3, p. 121-142, 2013. Disponível em: https://revistas.unicentro.br/index.php/capitalcientifico/article/view/1116/2119.

LO, P.; HE, M.; LIU, Y. Social inclusion and social capital of Shanghai Library as a community place for self-improvement. Library Hi Tech, v. 37, n. 2, p. 197-218, 2019. https://doi.org/10.1108/LHT-04-2018-0056.

LO, P.; PARK, A. Examining the relationship between social inclusion and mobile libraries in the age of Internet connectivity: A qualitative study of mobile librarians around the globe. Journal of Librarianship and Information Science, p. 1-26, 2020. https://doi.org/10.1177/0961000620935476.

MALHEIROS, M. B. et al. O papel da cultura organizacional na compreensão da diversidade organizacional: estudo em uma indústria de cosméticos. Gestión Joven, v. 21, n. 2, p. 47-65, 2020a. Disponível em: http://elcriterio.com//revista/contenidos $212 /$ Vol21 num2 4.pdf.

MALHEIROS, M. B. et al. Diversidade e inclusão social: estudo de caso em filial de uma rede de farmácias. Revista Unifeso - Humanas e Sociais, v. 6, n. 6, p. 38-52, 2020b.

MARCONI, M. A; LAKATOS, E. M. Fundamentos de metodologia científica. 6. ed. São Paulo: Atlas, 2009.

MATHIESON, J. et al. Social exclusion meaning, measurement and experience and links to health inequalities. World Health Organization, $\quad$ v. $\quad 1, \quad 2008 . \quad$ Disponível em: https://www.who.int/social determinants/media/sekn meaning measurement experience 2008.pdf.pdf?ua=1.

MEACHAM, H. et al. HRM practices that support the employment and social inclusion of workers with an intellectual disability. Personnel Review, v. 46, n. 1, p. 1-26, 2017. https://doi.org/10.1108/PR-05-2016-0105.

\section{MEIRELLES, V. R. C. COOPERATIVISMO COMO FORMA DE INCLUSÃO SOCIAL POR MEIO DA GERAÇÃO}

DE EMPREGO E RENDA: o caso da cooperativa de produção de recicláveis do Tocantins. Dissertação (Mestrado), $80 \mathrm{f}$, 2014. Programa de Pós-Graduação em Administração, Departamento de Economia, Contabilidade e Administração, Universidade de Taubaté, São Paulo, 2014.

MILKOVICH, G. T.; BOUDREAU, J. W. Administração de recursos humanos. São Paulo: Atlas, 2006.

MILLER, F. A. Strategic culture change: the door to achieving high performance and inclusion. Public Personnel Management, v. 27, n. 2, p. 151-160, 1998. https://doi.org/10.1177/009102609802700203.

NEPOMUCENO, M. F.; CARVALHO-FREITAS, M. N. As crenças e percepções dos gerentes e as possibilidades de trabalho das pessoas com deficiência. PEPSIC - Psicologia em Pesquisa, v. 2, n. 1, p. 81-94, 2008. Disponível em: http://pepsic.bvsalud.org/pdf/psipesq/v2n1/v2n1a10.pdf.

ORGAN, D. W. Organizational Citizenship Behavior: Recent Trends and Developments. Annual Review Of Organizational Psychology And Organizational Behavior, v. 5, n. 1, p. 295-306, 2018. https://doi.org/10.1146/annurevorgpsych-032117-104536.

PEREIRA, M.; SANCHES, I. R. Aprender com a diversidade: as metodologias de aprendizagem cooperativa na sala de 
aula. Nuances: estudos sobre Educação, v. 24, n. 3, p. 118-139, 2014.

PERLIN, A. P. et al. Inclusão de pessoas com deficiência no Mercado de Trabalho: um estudo em uma empresa do Setor Cerâmico. Desenvolvimento em Questão, v. 14, n. 34, p. 214-236, 2016. https://doi.org/10.21527/22376453.2016.34.214-236.

SILVA, C. L.; BOLSON, C. R.; FERIGOTTI, C. M. S. Tecnologia e inclusão social: cooperativa catamare. Interações (Campo Grande), v. 17, n. 3, p. 516-527, 2016. http://doi.org/10.20435/1984-042x-2016-v.17-n.3(13).

SILVA, P. M. M. Os desafios para a inclusão de pessoas com deficiência em organizações da construção civil. HOLOS, v. 7, n. 33, p. 311-327, 2017.

SILVER, $\mathrm{H}$. The contexts of social inclusion. United Nations Department of Economic and Social Affairs DESA Working paper, n. 144, 2016. Disponível em: https://papers.ssrn.com/sol3/papers.cfm?abstract id=2879940.

SOUZA, J. M. Inclusão de pessoas com deficiência: das políticas públicas ao preconceito. Revista Alcance, v. 24, n. 1, p. 22-35, 2017. https://doi.org/alcance.v24n1.p22-35.

SOUZA, A. A. A. et al. Empresa inclusiva? Uma análise comparativa entre os discursos de trabalhadores com deficiência e os de gestores de uma empresa cooperativa. Revista Gestão e Planejamento, v. 20, p. 218-238, 2019. https://doi.org/10.21714/2178-8030gep.v20.5688.

TAKET, A. et al. Practising Social Inclusion. Routledge: London, UK, 2013.

WALLERIUS, K; BISSANI, N. Inclusão de portadores com necessidades especiais no mercado do trabalho. Revista Tecnológica, v. 2, n.1, 2015. Disponível em: https://uceff.edu.br/revista/index.php/revista/article/view/18. 